Música, teatro e dança 


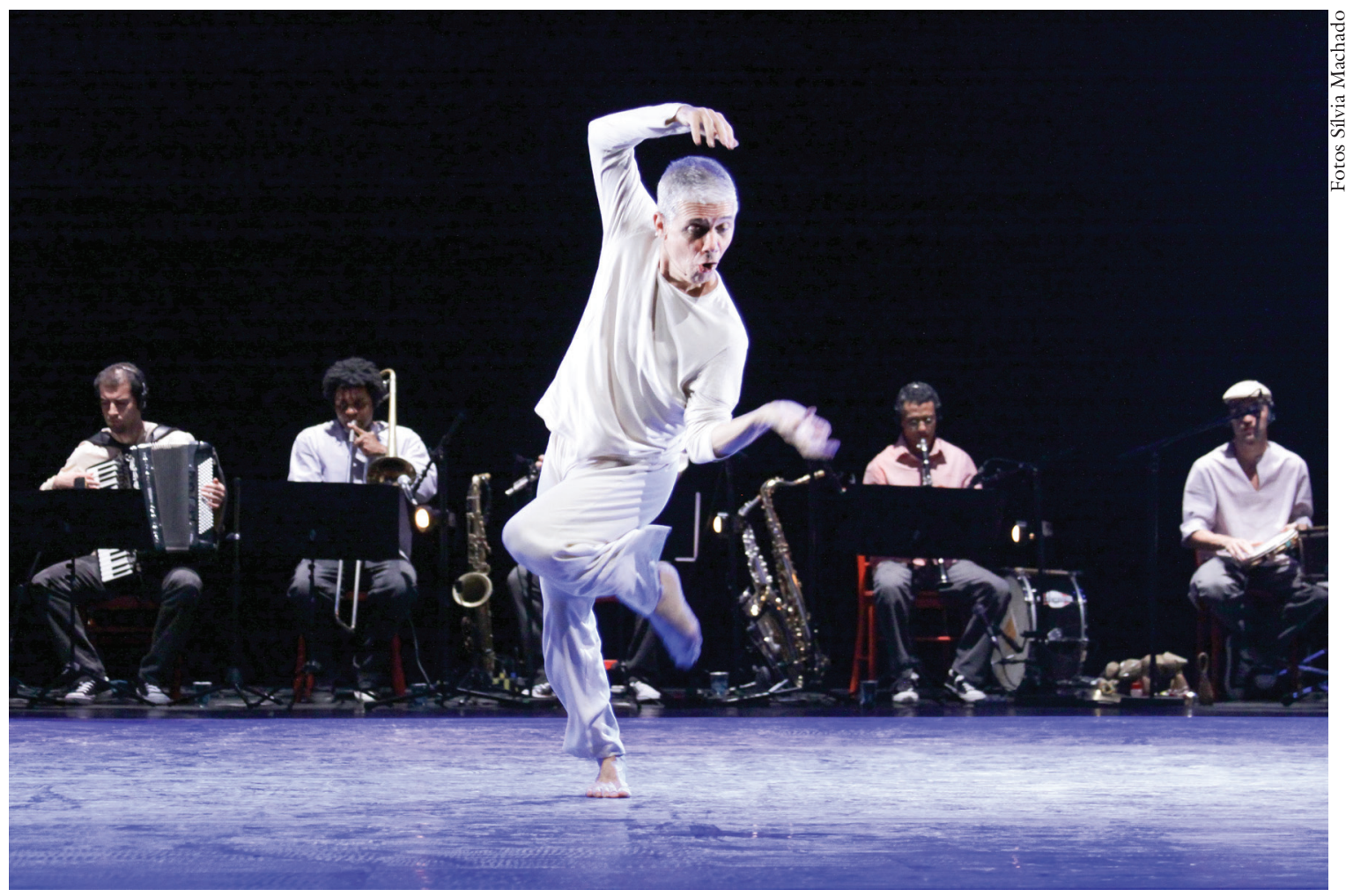

Antônio Nóbrega improvisando durante apresentação.

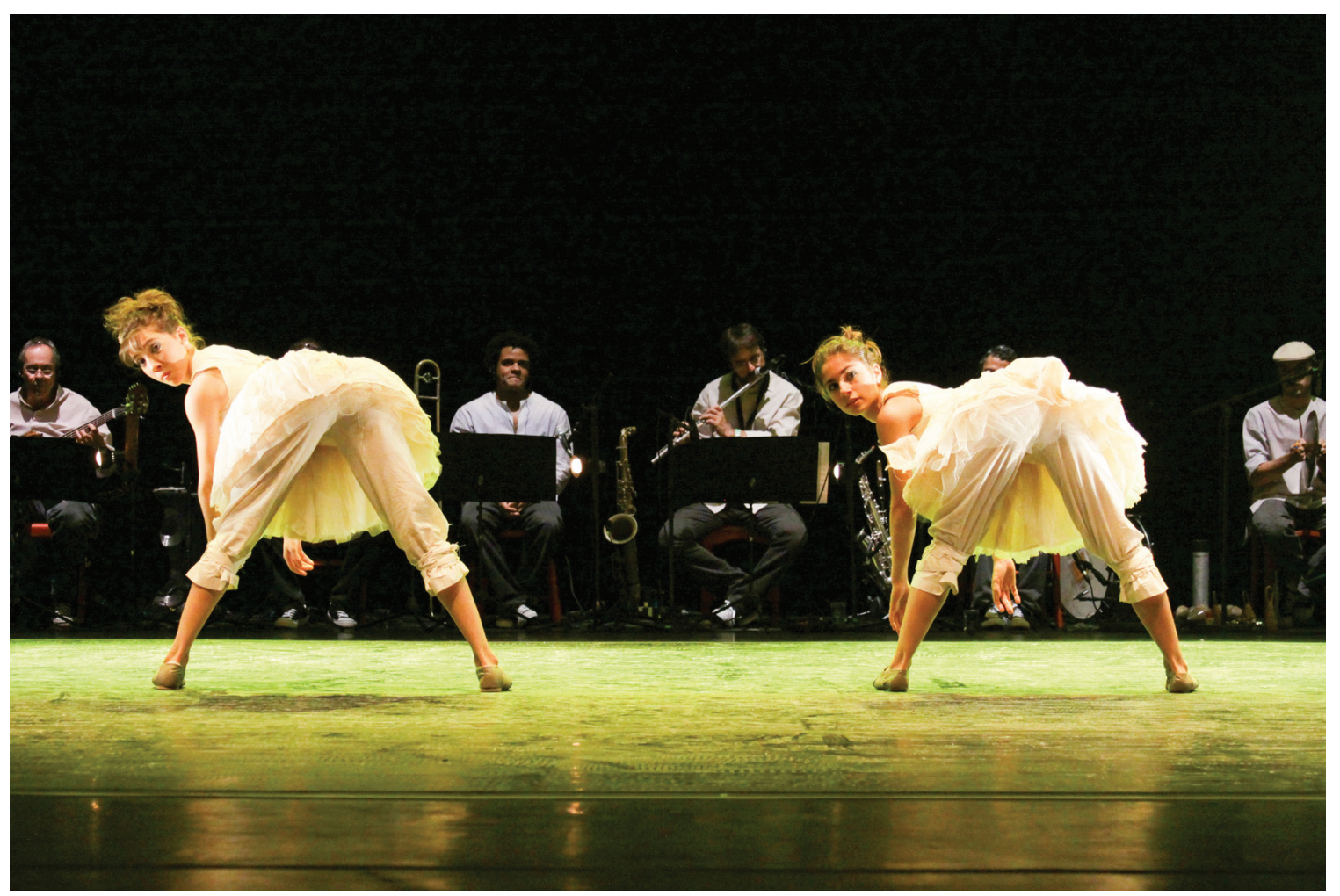

Maria Eugênia e Marina Abib em "Cabeça de Porco". 


\section{"Naturalmente - Teoria e jogo de uma dança brasileira" ANTONIO NOBREGA}

\section{Abrindo}

$\mathrm{E}$ M JulHo de 2009, no Teatro Paulo Autran da unidade Sesc Pinheiros de São Paulo, dei início às apresentações do espetáculo de dança "Naturalmente - teoria e jogo de uma dança brasileira”. Digo espetáculo, mas, na verdade, ele tanto poderia ser tratado como uma aula bem ilustrada ou como um espetáculo comentado. De qualquer maneira, aula-espetáculo ou propriamente espetáculo - como prefiro considerá-lo -, o fato é que essa minitemporada, para a minha grata surpresa, estava destinada a provocar um bom périplo de apresentações do espetáculo. Uma primeira e boa notícia chegou-me logo após a última apresentação desse fim de semana de estreia. Danilo Miranda, diretor do Sesc São Paulo, presente à ela, após a apresentação fez-me o convite para gravá-lo por intermédio da instituição que dirigia. E é claro que de imediato aceitei o convite. A gravação foi realizada em meados de 2010 e teve na sua direção o meu velho amigo e parceiro de outras tantas gravações e trabalhos Walter Carvalho. Do momento dessas suas primeiras apresentações até o registro em DVD, o espetáculo foi merecedor de prêmios e contou sempre com uma muito boa acolhida de público e crítica.

Mas eu dizia da minha surpresa pelo bom destino que o espetáculo veio a ter. Porque havia em mim uma certa dúvida, uma insegurança mesmo, em relação à sua natureza. Receava, fundamentalmente, que os textos nele inclusos não fossem de interesse geral do público e que terminassem por cansá-lo. Para minha sorte, não foi o que aconteceu. Na verdade, o que constatei foi uma generosa e interessada disposição do público em procurar acompanhar as falas. Penso que o fato de estarem organicamente ligadas às performances fez que o público as aceitasse fluidamente, como se fossem, me permitam, falas-dançantes... falas que se completavam com a movimentação dos corpos.

O presente texto é um registro ligeiramente ampliado daquelas falas. Aproveito a oportunidade de sua publicação para tentar aprofundá-las. Uma tarefa que venho me propondo realizar e que encontra nessa ocasião, portanto, um bom ensejo para começar.

Primeiramente, devo situar o leitor em relação ao espetáculo. Ele se inicia com a exibição, num imenso telão colocado ao fundo do palco, de uma multifacetada coletânea de momentos coreográficos de diversas danças populares brasileiras. Essas cenas foram tiradas da série televisiva Danças Brasileiras, prota- 
gonizada por mim e Rosane (minha mulher), idealizada por nós e pelo cineasta Belisário Franca que também a dirigiu.

Durante a exibição desse vídeo, de pouco mais de cinco minutos, eu, no violino, e um outro músico, o Zezinho Pitoco, na zabumba, executamos a trilha musical composta das seguintes obras: a polca Medrosa, de Anacleto de Medeiros; o frevo Corisco, de Lourival de Oliveira; e o baião Mourão, de Guerra Peixe. Logo após essa exibição dou inicio às falas.

\section{Primeira fala}

"Estou dando início a um espetáculo que guarda uma certa particularidade. Vem de longe o meu desejo de apresentar publicamente algumas considerações que venho elaborando sobre uma dança brasileira contemporânea de matrizes populares. Tomei o caminho de acondicionar essas considerações no corpo de um espetáculo. Decidido a isso, todavia, fui logo tomado por uma boa dose de apreensão: será que tal junção de performance e fala daria liga? Será que um espetáculo com esse subtítulo "Teoria e Jogo de uma Dança Brasileira" motivaria as pessoas? Depois de muito rodopiar dentro de mim, cheguei à conclusão final de que só poderia tirar essas dúvidas apresentando o espetáculo.

É por isso que estou aqui, gratificado pela presença de todos e agradecido ao Sesc por mais uma vez colaborar com meu trabalho artístico.

As imagens com as quais abrimos o espetáculo representam uma pequena amostra de passos, volteios, gingados, posturas, gestos e procedimentos coreográficos presentes no rico imaginário corporal popular brasileiro. Ele é fruto de um processo de miscigenação cultural que atravessa os nossos quatro primeiros séculos de formação. O Brasil foi um espaço aonde imemoriais heranças culturais se encontraram e deram origem a inúmeras manifestações artísticas de marcante presença corporal. Irei chamar de matrizes culturais fundadoras os cantos, narrativas, mitos, danças - ou fragmentos deles - provenientes das diversas nações africanas para aqui trazidas, das várias culturas indígenas aqui encontradas e dos diversos dialetos culturais ibéricos aqui aportados. É do encontro dessas matrizes fundadoras que, lenta e pacientemente dialogando entre si, nascem as primeiras matrizes culturais brasileiras. Os nossos folguedos, danças, cantos, mitos e narrativas nascem, portanto, desse processo de mestiçagem cultural. No caso da dança, esse sincretismo de matrizes dá origem a um rico caldeirão de manifestações que se derrama por todo o país. Podemos dizer que essas manifestações se agrupam em torno de algumas famílias. Uma das principais é a dos batuques. Coreograficamente, têm em comum a forma de roda, o sapateado, o bater de palmas e, sobretudo, a umbigada ou a insinuação dela. Pelo lado musical, o canto refrão-estrofe (prevalentemente em quadras de sete sílabas) e a utilização de uma percussão à base de tambores tocados com as mãos, de dimensões diversas, $\mathrm{e}$, no geral, dispostos verticalmente no chão. Alguns grupos se utilizam também do ganzá, do reco-reco, do pandeiro, da alfaia e por vezes de uma lata percutida com varetas, caso do coco-de-zambê. A proveniência da família dos batuques 
remonta às reuniões festivas, práticas e celebrações religiosas - os ditos calundus - realizadas pelos negros em seus ajuntamentos, senzalas e quilombos durante o nosso largo processo de colonização. Com peculiaridades regionais e diferentes nomes esse gênero de manifestação se acha presente em todo o país. Coco de roda, praiano ou simplesmente coco, em Pernambuco, Alagoas e Paraíba; coco-de-zambê, no Rio Grande do Norte; samba rural, no interior baiano; tambor-de-crioula, no Maranhão; jongo, no Rio; batuque, em São Paulo; carimbó, no Pará etc. É dessa família, ainda, de onde provém o nosso samba, palavra derivada de semba, que em banto quer justamente dizer umbigada.

Uma segunda família é a dos cortejos. São manifestações diretamente descendentes do antigo procedimento colonial de coroação dos Reis de Congo. Reis negros quase sempre escravos, eleitos por outros cativos, com anuência interessada da própria coroa, tinham poderes de "governar" uma determinada comunidade comumente denominada de nação. Nos dias da coroação desses reis negros, bem como naqueles dedicados às celebrações religiosas dos santos negros como N. Sra. do Rosário e São Benedito, eram organizados festivos cortejos-espetáculos. A música a puxar tais séquitos - ainda hoje em plena atividade - é constituída de cantos - toadas, loas e benditos - animados por uma sonorosa percussão formada por robustos tambores e caixas-de-guerra ou taróis. Coreograficamente, além dos passos e movimentos utilizados durante o deslocamento do cortejo e, em alguns, o jogo dos bastões, representações de danças-mimadas simulando passados combates de reminiscências africanas, continuam a integrar o desfilar de muitos desses préstitos. É nessa família onde estão os moçambiques, os maracatus, as congadas, os congos, os cucumbis, as taieiras, entre outros.

A terceira e mais vistosa dessas famílias é dos espetáculos ou folguedos populares propriamente ditos. Têm uma ascendência ligada, especialmente, às janeiras e reisadas portuguesas: grupos processionais e peditórios que jornadeavam por casas, ruas e povoações louvando e cantando o nascimento do deus menino e a chegada dos reis magos na época da Natividade cristã - solstício de verão europeu. Peregrinavam ao som de violas, rabecas, cavaquinhos e instrumentos de percussão. No Brasil, esses pequenos grupos caminheiros - também conhecidos pelos nomes de ternos e ranchos -, ao longo dos séculos, foram incorporando às suas andanças tipos e figuras teatrais provenientes de diversas fontes, tais como, cancioneiro, romanceiro, personagens populares, mitos etc. Assim, ao visitarem as casas para pedir "as sortes" ou "tirarem reis", tais figuras dramáticas, apresentadas na forma de pequenos entremeios ou entrechos dialogados, mimados, dançados ou cantados eram exibidas. São esses pequenos grupos itinerantes, portanto, que, no Brasil, vão ganhar o nome de reisados. Cada um desses reisados se intitulava a partir do nome de uma das suas figuras mais representativas. Assim, havia o reisado do João do Vale, o do pinica-pau, o do Jaraguá, o do cavalo-marinho etc. Com o passar do tempo, tais grupos vão aglutinando vários reisados num só, vão perdendo o seu caráter deambulatório 
e tornando-se uma trupe-de-brincantes que se fixam numa determinada região para a apresentação de sua numerosa galeria de tipos e figuras. São esses reisados que paulatinamente vêm se firmar com os nomes de bumba-meu-boi, cavalo-marinho, boi-bumbá, boi-de-mamão, boi-de-reis, cordão-de-bichos, auto-dos-guerreiros etc. A presença e persistência do nome boi ligado à maioria desses espetáculos se deve ao fato de ser o entrecho dramático do boi aquele tanto de maior significado mágico-religioso - identificado com o complexo morte-ressurreição - quanto o de maior sedução e encantamento espetacular devido às estripulias, investidas e galhofarias dessa figura-totem - êh, bumba, meu boi! São esses "brinquedos" ou "brincadeiras" (denominações dadas ao folguedo pelos seus próprios integrantes) espetáculos-hospedeiros totais, pois abrigam a dança, o canto, a música instrumental, a comédia, o drama, o recitativo, a pantomima etc. A música nesses folguedos é de vital importância. Normalmente executada por pequenos conjuntos formados por instrumentistas-cantores, que tanto "tiram" os toques instrumentais quanto as loas e cantigas, é ela que conduz todo o espetáculo. Conforme a região, são utilizados instrumentos de cordas e de harmonia como a rabeca (nome dado popularmente ao violino), a viola, o cavaquinho, o violão e o acordeom; e de uma variada percussão composta de pandeiro, ganzá, reco-reco, surdo, caixa etc. Uma pequena orquestra instrumental e vocal, portanto, que dá toda a "sustança anímica" para o desaguar de um estonteante e caleidoscópico imaginário cultural. Quem quiser comprovar isso que estou dizendo basta acompanhar a apresentação de um cavalo-marinho em algum lugar de terra batida de um pequeno povoado da zona canavieira da mata norte pernambucana, entre os meses de novembro a janeiro, do meio da noite de sábado até o amanhecer do domingo. Ali, sob os pés ágeis da "tropelada" dos brincantes no "mergulhão", a poeira sobe e o chão treme... Ao acompanhar tais espetáculos penso nos grandes gêneros de teatro-dança asiáticos: o kathakali indiano, o kabuki japonês, o barong balinês, a ópera de Pequim, formas espetaculares que vêm inspirando encenadores europeus e americanos como Bob Wilson, Peter Brook, Ariane Mnouchkine, dentre outros.

Além dessas famílias principais, contamos ainda com aqueles particulares núcleos difusores de uma também rica cultura corporal. É o caso da capoeira, do passo do frevo, das danças dramáticas como os congos e a nau catarineta, das danças afro-brasileiras ligadas ao culto dos orixás, entre outras."

Assim concluo a minha primeira fala. Ela antecede à primeira coreografia a ser apresentada: uma pequena suíte de danças populares. Uma viagem coreográfica através dos movimentos e procedimentos característicos de algumas danças populares como o caboclinho, o cavalo-marinho, o maracatu rural, a capoeira e o frevo.

Em seguida à apresentação dessa suíte, pedindo à plateia que procure guardar duas coisas importantes desse passeio coreográfico - o vocabulário (passos, giros saltos etc.) e o temperamento com o qual esse vocabulário se mexe -, continuo. 


\section{Segunda fala}

"De maneira geral, são esses os dois itens principais que constituem uma linguagem de dança. Eles estão presentes, por exemplo, na dança clássica europeia; nas danças clássicas da Índia; nas danças de Bali; na dança Flamenca, entre outras linguagens de dança. E é interessante constatar que todas essas linguagens tiveram nos seus processos de gestação um fecundo vínculo com as matrizes ancestrais e coletivas de suas culturas. Tome-se como exemplo o balé clássico que, nas suas origens assimilou passos da pavana, da sarabanda, da giga, do minueto, da bourré (pas de bourré), danças que eram, por assim dizer, os caboclinhos, os batuques, as congadas e folias da cultura europeia.

O ponto de partida dessa minha tentativa de codificar uma certa linguagem brasileira de dança foi a reunião de passos, saltos, giros, quedas etc. - o imaginário vocabular - das várias danças entre si. Por meio desse procedimento foi possível a constituição de um extenso e variado vocabulário-síntese. Uma nova e abrangente síntese, porque, na verdade, as nossas danças populares são o resultado das colagens realizadas em várias regiões do Brasil de danças ou de fragmentos delas - indígenas, africanas e ibéricas - que se desmantelaram no processo de acomodação colonizadora. Para nossa sorte, todavia, esse desmantelamento não pode impedir que esses fragmentos se colassem e se reorganizassem em outras configurações dando origem a novos dialetos corporais, ou seja, às diversas danças populares das várias regiões brasileiras, de grande riqueza simbólica e potencial coreográfico.

Um dos objetivos das minhas falas nesse espetáculo é mostrar como, a partir dessa reunião de movimentos, proponho a sua articulação e combinação. Mas isso nós veremos depois da apresentação de alguns solos e duetos. Neles, os passos são desvinculados dos universos folclóricos de onde provêm e se abrem para novas configurações expressivas."

Assim eu fechava a segunda fala.

Eram dançadas, então, as seguintes obras musicais: "Tempo de caboclinhos" (Ernani Aguiar); "Cabeça de porco" (Anacleto Medeiros) e "Suíte cinema" (Rota e Chaplin) por Maria Eugênia e Marina Abib; "Guerreiro" (Antonio Madureira) e "Gaiata" (excerto da suíte Quebra nozes de Tchaikóvski) por mim.

Dou início à terceira fala com a seguinte pergunta:

\section{Terceira fala}

"Como configuro tecnicamente essa linguagem?

- Em primeiro lugar: articulando e combinando o conjunto de movimentos reunidos das diversa danças - o vocabulário ou léxico se assim preferirmos nomeá-lo - a partir da fixação de algumas posições-base. Essas posições-base são oriundas do próprio universo das danças e são elas que, além de darem unidade formal e estrutural ao vocabulário, propiciam ao bailarino uma energia adicional de grande importância para o seu desempenho. A partir delas posso não só mapear todo o universo de movimentos e passos daquele vocabulário-síntese, como 
desmembrar cada um desses movimentos e passos em unidades vocabulares menores. Na verdade, todas aquelas linguagens de dança a que me referi lá atrás se alicerçam e se estruturam também a partir de determinadas posições. Na dança clássica da tradição europeia, por exemplo, há cinco."

Apresento, então, alguma dessas posições fazendo um pequeno paralelo com aquelas presentes em outras linguagens de dança como o kathakali indiano, o barong balinês etc. Quando sinto que a plateia demonstra um certo interesse maior no assunto, me alongo um pouco mais demonstrando como faço o desmembramento dos passos em unidades ainda menores, em "passitos", como gosto de dizer aos bailarinos que trabalham comigo.

E continuo:

"Em segundo lugar: explorando e potencializando um certo temperamento comum na maneira como esse vocabulário se move. Quando comecei a estudar e aprender as danças populares, senti que elas tinham alguma coisa de muito peculiar e significativo em comum. Notava que havia na maneira de se movimentar dos dançarinos, para além do vocabulário, um determinado jeitão que se refletia em molejos, gingados, balanços, meneios, negaças, espasmos, requebros etc. De onde vinha isso? O que fazia gerar esses procedimentos? A que correspondia tudo isso, tecnicamente falando?

Observando e estudando mais atentamente as danças, fui compreendendo que esse jeitão particular de ser, isso que chamo de temperamento, era um reflexo direto do espírito da música que as animava. Uma música cujo caráter era significativamente marcado pela presença e valorização de tempos contramétricos ou contratempos e tempos sincopados só podia dar origem àqueles peculiares procedimentos corporais. Para quem não sabe, a síncope é uma espécie de alteração rítmica que consiste no prolongamento do som de um tempo fraco num tempo forte. Normalmente fazemos a marcação do tempo musical através desse movimento..."

É claro que para a maioria das pessoas esse enunciado não é suficiente para que se possa compreender o que realmente vem a ser essa tal de síncope... E é por isso, então, que nesse momento, procurando demonstrar melhor à plateia do que ela se trata, informo que normalmente o tempo musical é composto de tempos fortes e fracos (contramétricos ou contratempos) e que o tempo sincopado fica justamente entre eles. Faço essa explanação batendo o tempo com as mãos e mostrando que quando a mão desce marca o tempo forte, quando sobe, o fraco, e que entre eles, atravessando-os, está a síncope.

Em seguida, para que fique ainda um pouco mais clara a questão, peço às duas bailarinas que dancem dois ritmos populares onde a síncope é facilmente localizável: o samba de parelha (gênero da família dos batuques) e o maracatu (um cortejo).

Fecho essa última fala tocando o choro "Simplicidade" de Jacob do Bandolim e dizendo ainda ao público que esse gênero de música instrumental bra- 
sileira tem justamente como uma de suas grandes características o de ser uma forma musical bastante sincopada.

Depois da apresentação do choro, volto ao meu texto ainda mais uma vez:

\section{Fechando}

“Concluindo essas falas, resta-me dizer que para a elaboração dessa Teoria e Jogo de uma dança brasileira, tive de recorrer também ao que chamo do Grande Fundo Patrimonial e Universal da Cultura. Com isso quero dizer que, para além do estudo e convivência com os artistas populares, muito me vali de estudos que também empreendi sobre várias linguagens de dança-teatro tanto do Ocidente quanto do Oriente; muito me vali da leitura de obras sobre a arte do ator e do dançarino, em especial aquelas do encenador e teórico italiano Eugenio Barba; e, sobretudo, muito me vali das aulas que tive a alegria de desfrutar do saudoso amigo, mentor e coreógrafo Klaus Vianna.

Esse trânsito de conhecimentos entre o universal ou geral e o local ou particular tem para mim uma dimensão simbólica que eu gostaria que esse espetáculo pudesse refletir. Reparem: teoria e jogo, fala e performance, tempo forte e tempo fraco, danças marcadas por uma energia masculina e outras pela feminina... são procedimentos, categorias ou modos de ser tão opostos quanto complementares. Harmonizar, conciliar, buscar o equilíbrio desse constante jogo de contrários talvez tenha sido aquilo que mais procurei com o meu espetáculo. Se posso aspirar a alguma transcendência para ele seria essa. Ou seja, a reafirmação do espírito de confraternização entre os opostos, uma das maiores pendências civilizacionais que, a meu ver e sentir, carregamos. A civilização europeia ou ocidental, cujos padrões e valores, em quase todos os sentidos, são hodiernamente hegemônicos, nos oferta, ao lado de sua extraordinária riqueza civilizatória, tecnológica e cultural, um mundo também de enormes contradições e perdas. Dispõe-nos um sistema-mundo de terríveis antagonismos. Um sistema-mundo onde os opostos continuamente se incompatibilizam impedindo o necessário e fecundo jogo da alteridade entre eles. Um mundo de natureza bipolar. Daí: desenvolvimento tecnológico extraordinário reservado a uma restrita parcela dos habitantes do planeta. Enorme riqueza concentrada - hiperconsumismo contrastando com a vastidão da pobreza e da exclusão. Razão instrumental ou pragmática hiperatrofiada versus obscurantismo atroz. Um sistema-mundo de tal maneira dicotomizado cujos sintomas se instauram dentro do mundo da arte e cultura de todas as maneiras possíveis. Tome-se como exemplo o caso da música onde pelos padrões ocidentais existe continuamente a necessidade de bifurcá-la entre erudita e popular. Alta e baixa cultura. Chega a parecer que inexiste um território de natural e fértil diálogo, de real sincretismo entre dois modos de ser que só na aparência são inconciliáveis. (É bom nos lembrarmos de que tanto a orquestra sinfônica quanto o rock são imbricações de um mesmo mundo cultural. Cada qual recalque do outro. Dois mundos para cuja escuta são necessárias duas atitudes diametralmente opostas.) Mas acabamos de escutar o 
choro "Simplicidade" de Jacob do Bandolim. Trata-se de uma música popular ou erudita? Não será que esse gênero de música fica exatamente no miolo, na linha fronteiriça entre esses dois conciliáveis mundos? Uma música tão popular quanto erudita, ou seja: tanto articulada dentro de um pulso rítmico (base da música popular), interpretada através de um fraseado "mais livre", quanto apoiada em padrões de harmonização, contraponto e execução sofisticados. E não se trata de uma música popular eruditizada ou de uma música erudita rebaixada. Trata-se de uma música "organicamente" tão erudita quanto popular, tão sensorial quanto cerebral, tão apolínea quanto dionisíaca. (Vale dizer que o jazz, apesar de suas naturais diferenças para com o choro, tem em comum com ele essa mesma disposição à ambiguidade de tanto ser uma música que nos toma pelos sentidos quanto pelo intelecto, que nos instiga à dança e à quieta escuta simultaneamente.) Mas continuemos. A dança do frevo pernambucano, bem como a música que lhe é geminada, parece também desfazer essa ideia de opostos não conciliáveis, porque conjuminando todos os opostos possíveis, ela os integra num contínuo jogo ou numa simbiose perfeita aonde os tempos fortes, contramétricos e sincopados da música se imiscuem visceralmente, "interno-dialeticamente", convidando o dançarino a expressar-se contidamente, desbragadamente, geometricamente, arrebatadamente, pirotecnicamente, religiosamente... sei lá de modo mais o quê. E o que dizer de nossa capoeira? Onde já se viu um tal florilégio de movimentos marciais (golpes de ataque e defesa) misturados à gingados, fintas, saltos, procedimentos acrobáticos, contorções saracoteadas etc., tudo isso sob o impulso profundo do espírito da música? De onde vem esse espírito? (E antes de tentar responder a essa questão, mais esse parêntese para lembrar que o frevo é filho da capoeira). Repito a pergunta: de onde vem esse espírito?

Vem do fato de que a nossa linha de tempo cultural popular guarda padrões de comportamento, formas, modos, conteúdos, representações simbólicas, valores, estruturas, características e procedimentos [...] que: ou foram deixados de lado pela marcha civilizatória e cultural da linha de tempo hegemônica europeia ou ocidental ou nunca por ela foram visitados - o que no meu entendimento é menos provável. A meu ver, a grande novidade é que o novo ainda está vivo. Há ainda um novo sopro de humanidade no ar... Um novo cuja ordem do dia, em todos os sentidos, não é a de separar, mas sim a de reunir, integrar, sincretar, mestiçar. E esse novo dormita principalmente nas jovens culturas e naquelas que tiveram no dinamismo de seus desenvolvimentos um vínculo mais ativo com o universo sensorial, gregário, afetivo e simbólico. Naquelas onde a visão dicotômica do mundo mais se diluiu, onde a imagem do céu e do inferno de alguma maneira mais se embaralhou... Onde a representação psíquico e religiosa do mundo é tão masculina quanto feminina. A linha de tempo cultural popular brasileira correu uma trajetória muito singular e expressiva, repleta de novos signos. Um desses seus signos é representado pela plasticidade que temos em saber dialogar com o diferente. Esse é um daqueles dos nossos signos que ainda na 
maioria das vezes temos sabido utilizá-lo positivamente. A nossa mestiçagem é umas das provas mais eloquentes dessa constatação. Uma mestiçagem que também se revela através do caráter sincrético da cultura com a qual ela se gemina e que nos dá, de bandeja, um país tão uno quanto culturalmente diverso. Mas isso não quer dizer, no entanto, que temos sabido nos utilizar positivamente de todo o caleidoscópico de signos, conteúdos e valores criados dentro da nossa linha de tempo cultural popular. Esta aí o jeitinho brasileiro a nos desmoralizar continuamente. Na verdade, esses valores, conteúdos e signos tanto podem ajudar-nos a nos desembaraçar das amarras a que o lado envelhecido e exaurido da linha de tempo cultural ocidental nos tem submetido, quanto, desajudando-nos, aprofundar ainda mais essa submissão. Cabe-nos ainda, e prioritariamente, a sempre adiada tarefa de melhor nos conhecermos, compreendermo-nos para que, e só depois, possamos ter a sabedoria de escolher o que cada uma dessas duas linhas de tempo, no tempo da chamada modernidade, têm de melhor para nos oferecer. Aonde elas se imbricam para produzir a grande linha de tempo cultural Brasil. Nem popular, nem erudita, nem universal, nem regional, e ao mesmo tempo tudo isso. E, à falta de um outro nome qualquer, brasileira. Planetariamente brasileira. Essa conciliação, a meu ver, eis a nossa grande e vital tarefa. A ela, portanto.

Meus amigos, é dentro dessa perspectiva que para mim se apresenta a questão Cultura Popular.

Finalizando: não será, portanto, essa nossa linha de tempo cultural que tenho preferido chamar de Mátria um dos essenciais polos de irradiação cultural? Uma das mais vigorosas fontes e reservas de cultura de que dispomos para o rejuvenescimento e balanceamento cultural do mundo? Com o "Naturalmente", tentando estabelecer esse diálogo através do universo da dança, procurei sugerir uma alternativa. Um caminho que possibilitasse, entre outras coisas também, uma compreensão mais verdadeira de onde estão o velho e o novo, o arcaico e o moderno.

Era isso o que eu tinha para dizer.

Com as três últimas coreografias a serem apresentadas em seguida, dou quase por encerrado o espetáculo dessa noite. Muito obrigado.”

Danço eu, então, a abertura da suíte em Ré Maior de Bach; dança Marina Abib a "Gnossienne n ${ }^{\circ}$ l" de Erik Satie; e dança Maria Eugênia o choro "Santa Morena" de Jacob do Bandolim.

Ao final dessas danças, volto pela última vez ao palco e falo:

“O 'quase por encerrado' da fala anterior remete a um comentariozinho que ainda eu gostaria de fazer.

Já quase pronto o espetáculo e eu só tinha para lhe dar como nome o "Teoria e jogo de uma dança brasileira". Um nome inspirado no título de uma conferência do poeta espanhol Garcia Lorca - "Teoria y juego del Duende" - 
em que ele homenageia a cantadeira espanhola Pastora Pavan. Percebi que esse era um nome que funcionaria bem como subtítulo do meu espetáculo. Mas aonde estava o nome propriamente dito do espetáculo? Foi conversando sobre essa questão com Rosane, minha mulher, e comentando ao mesmo tempo sobre uma música que na ocasião me dava muito prazer em ficar dançando e improvisando, que ela me sugeriu dar ao espetáculo o nome dessa música. Topei de pronto. Essa música é de autoria de um dos nossos maiores compositores, Dominguinhos, que a compôs à maneira de um improviso durante a gravação de um show. O mais curioso é que só quando o seu produtor lhe pediu o nome da música para poder colocar no encarte é que ele pensou no assunto... Naturalmente.

RESUMO - "Naturalmente - Teoria e jogo de uma dança brasileira" é o nome de um espetáculo de dança criado por Antonio Nobrega em 2009. Nele, o seu criador, procura conciliar a performance com a fala. Ou seja, falas entremeiam coreografias e, ambas, procuram trazer à tona uma questão pouco presente no cenário da dança no Brasil: a existência ou não de uma dança brasileira. Nobrega procura responder afirmativamente a essa questão organizando uma linguagem de dança que tem como base de exploração as matrizes corporais presentes no rico imaginário das danças e manifestações populares brasileiras - fruto do sincretismo índio-negro-ibérico-popular - em diálogo com o universo da técnica desenvolvido pela cultura da dança ocidental. O presente texto corresponde a uma versão mais aprofundada em relação aquele apresentado durante as apresentações do espetáculo. É, como ele tem afirmado, um seu ponto de partida para uma discussão mais atual sobre a ainda mal resolvida questão cultura popular.

PALAVRAS-CHAVE: Dança, Cultura popular, Matrizes culturais, Síncopa, Patrimônio universal da cultura.

ABSTRACT - "Naturalmente - Teoria e jogo de uma dança brasileira" ("Naturally - Theory and game of a Brazilian dance") is the name of a dance created by Antonio Nobrega in 2009, in which its creator seeks to reconcile performance and speech. To this end, spoken lines are interwoven with the choreography, and both strive to fathom an issue that is rarely discussed in Brazil's dance milieu, namely, whether a distinct Brazilian dance exists or not. Nobrega attempts to answer affirmatively by organizing a dance language based on the body matrices found in the rich imagery of Brazilian folk dances and manifestations - deriving from Indian/Black/popular Iberian syncretism - and establishing a dialogue with the universe of the techniques developed by Western dance culture. This text is more profound version of the one offered during the presentations of the show. As Nobrega has stated, it is a starting point for a renewed discussion on the still-unresolved question of popular culture.

KEYWORDS: Dance, Popular culture, Cultural matrices, Syncopation, Universal Heritage of culture.

Antonio Nóbrega é artista e músico. @ - brincantenobrega@gmail.com

Recebido em 11.7.2012 e aceito em 6.8.2012. 